\title{
Meteorological table, for July 1806
}

\author{
Mr. Carey
}

To cite this article: Mr. Carey (1806) Meteorological table, for July 1806, Philosophical Magazine Series 1, 25:98, 192-192, DOI: 10.1080/14786440608563433

To link to this article: http://dx.doi.org/10.1080/14786440608563433

曲 Published online: 18 May 2009.

Submit your article to this journal $2 \pi$

LII Article views: 2

Q View related articles $₫$ 
METEOROLOGICAL TABLE, By Mr. Cakey, of the STrand,

For July 1806.

\begin{tabular}{|c|c|c|c|c|c|c|}
\hline \multirow[b]{2}{*}{$\begin{array}{l}\text { Days of the } \\
\text { Month. }\end{array}$} & \multicolumn{3}{|c|}{ Thermometer. } & \multirow[b]{2}{*}{$\begin{array}{l}\text { Heigne of } \\
\text { the } \mathrm{B}_{d} \text { orr. } \\
\text { Inches. }\end{array}$} & \multirow{2}{*}{ 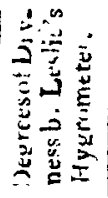 } & \multirow[b]{2}{*}{ Weather. } \\
\hline & 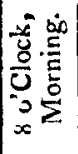 & $\begin{array}{l}\dot{8} \\
\dot{8} \\
z\end{array}$ & 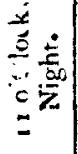 & & & \\
\hline June 27 & $56^{\circ}$ & $.57^{\circ}$ & $49^{\circ}$ & $29 \cdot 82$ & $10^{\circ}$ & Showery \\
\hline 28 & 50 & 61 & 50 & $30 \cdot 00$ & 51 & Fair \\
\hline 89 & 56 & 63 & 59 & .20 & 56 & Fair \\
\hline 30 & 69 & 65 & 59 & $29 \cdot 90$ & $\mathbf{0}$ & Rain \\
\hline July 1 & 59 & 64 & 57 & $30 \cdot 00$ & 46 & Cloudy \\
\hline 2 & 60 & 66 & 61 & $\cdot 15$ & 51 & Fair \\
\hline 3 & 63 & 72 & 66 & .01 & 54 & Fair \\
\hline 4 & 63 & 68 & 55 & 29.89 & 25 & Cloudy \\
\hline 5 & 60 & 69 & 60 & .90 & 50 & Fair \\
\hline 6 & 60 & 55 & 56 & $\cdot 81$ & $\mathbf{0}$ & Rain \\
\hline 7 & 59 & 64 & 58 & .52 & $\mathbf{0}$ & Rain \\
\hline 8 & 60 & 68 & 63 & $\cdot 62$ & 25 & Cloudy \\
\hline 9 & 60 & 74 & 64 & $\cdot 92$ & 24 & Cloudy \\
\hline 10 & 65 & 77 & 68 & $30 \cdot 08$ & 47 & Fair \\
\hline 11 & 74 & 72 & 60 & $29 \cdot 88$ & 0 & $\begin{array}{l}\text { Rain, with } \\
\text { thunder }\end{array}$ \\
\hline 12 & 63 & 71 & 65 & $30 \cdot 00$ & 56 & Fair \\
\hline 13 & 66 & 76 & 68 & $29 \cdot 90$ & 47 & Fair \\
\hline 14 & 68 & 68 & 64 & $\cdot 68$ & $\mathbf{0}$ & Showery \\
\hline 15 & 64 & 70 & 62 & $\cdot 80$ & 35 & Fair \\
\hline 16 & 60 & 71 & 55 & $\cdot 64$ & 58 & Fair \\
\hline 17 & 62 & 66 & 57 & $\cdot 70$ & 0 & $\begin{array}{l}\text { Showery, with } \\
\text { thunder }\end{array}$ \\
\hline 18 & 60 & 58 & 55 & -76 & $\mathbf{0}$ & Showery \\
\hline 19 & 55 & 66 & 55 & $\cdot 83$ & 40 & Fair \\
\hline 20 & 56 & 66 & 54 & $\cdot 93$ & 45 & Cloudy \\
\hline 21 & 55 & 66 & 54 & $\cdot 80$ & 0 & Showery \\
\hline 22 & 56 & 68 & 57 & .78 & 46 & Fair \\
\hline 23 & 57 & 70 & 56 & $\cdot 50$ & $\mathbf{0}$ & Showery, \\
\hline 24 & 58 & 69 & 57 & $\cdot 61$ & $\mathbf{0}$ & $\begin{array}{l}\text { Thunder, with } \\
\text { great fall of } \\
\text { rain }\end{array}$ \\
\hline 25 & 57 & 67 & 56 & $29 \cdot 60$ & 43 & Fair \\
\hline 26 & 58 & 70 & 58 & .59 & 50 & Fair \\
\hline
\end{tabular}

N, B. The barometer's height is taken at noon.

ERRatom-Vol, xxv, p. 12. line 8., article Electricity, for loaded jar read coated jar. 